\title{
Integração de recursos para acesso aos Objetos de Aprendizagem Multimodais
}

Núbia dos Santos Rosa Santana dos Santos, PPGIE/UFRGS, nubrosa@ gmail.com José Valdeni de Lima, PPGIE/UFRGS, valdeni@inf.ufrgs.br Leandro Krug Wives, Instituto de Informática/UFRGS, wives@inf.ufrgs.br

\begin{abstract}
Resumo. Considerando os diferentes meios de acesso aos conteúdos educacionais tais como computador, mídia impressa, dispositivos móveis, etc. e as limitações de cada meio, deve-se atentar para a elaboração de conteúdos que possam ser acessados por diferentes meios, independente de local ou situação. Este artigo analisa algumas possibilidades de acesso a Objetos de Aprendizagem, bem como as preferências dos alunos em relação aos meios utilizados para estudo. Nesse contexto, o artigo apresenta uma proposta de OA e alguns resultados referentes à utilização do OA proposto.
\end{abstract}

Palavras-chaves: mídia impressa, mobilidade, objetos de aprendizagem

\section{Integration of resources for access to Multimodal Learning Objects}

\begin{abstract}
Considering the different means of access to educational content such as computer, print media, mobile devices, etc., and limitations of each means, should to attention to the development of content that can be accessed by different means, regardless of location or situation. This article examines some possibilities of access to learning objects, as well as the preferences of students in relation to the means employed to study. In this context, the paper presents a proposal for $\mathrm{LO}$ and some results concerning the use of LO.
\end{abstract}

Keywords: printed media, mobility, learning objects

\section{Introdução}

Os meios utilizados para acessar um conteúdo educacional podem ser diversificados, e ao mesmo tempo complementares considerando as limitações existentes em cada meio. Em relação ao uso de material impresso na EaD, os dados do censo Ead.br 2008 (2010) mostram que $87,3 \%$ das instituições o utilizam, seguido pelo e-learning $(71,5 \%)$ e pelo vídeo $(51,7 \%)$. Ou seja, o material impresso ainda é muito utilizado no ensino. No entanto, conforme aponta Belisário (2006), a mídia impressa caracteriza-se pela pouca interatividade, servindo mais para a leitura do que para estudo do material. Em relação ao computador, o mesmo autor aponta limitações, como a falta de hábito de leitura na tela por parte do usuário, problemas de acesso ao material e a necessidade de um ambiente adequado, mas destaca a possibilidade da interação. 
Nesse contexto, as dificuldades existentes no acesso ao conteúdo em virtude das limitações do meio utilizado podem ser reduzidas ao elaborar conteúdos que possam ser acessados por diferentes recursos de forma complementar. Além disso, conforme aponta Masetto (2007), o processo de aprendizagem abrange o desenvolvimento intelectual e afetivo, o desenvolvimento de competências e de atitudes. Isso nos leva a crer que um conteúdo educacional deva utilizar diferentes meios, não ficando limitado a um único meio, tecnologia ou técnica. Além disso, Masetto (2007, p.143) também destaca que "não podemos ter a esperança de que uma ou duas técnicas, repetidas à exaustão, deem conta de incentivar e encaminhar toda a aprendizagem esperada". Dessa forma, considerando que existem diferentes formas de acesso aos conteúdos educacionais e que o aluno teria maiores benefícios combinando-as, devemos analisar diferentes maneiras para planejar um conteúdo utilizando recursos, mecanismos e meios complementares. Nesse contexto, este artigo apresenta uma proposta de Objetos de Aprendizagem (OAs) Multimodais que possam ser acessados por diferentes meios, inclusive pela mídia impressa integrando a tecnologia de códigos 2D, e utilizados no ensino à distância, bem como no ensino presencial.

O artigo está estruturado da seguinte forma: a seção 2 apresenta o OA multimodal proposto e alguns conceitos relacionados. A seção 3 apresenta um estudo realizado com alunos usando o OA e alguns resultados parciais. A seção 4 apresenta as considerações finais.

\section{Objeto de Aprendizagem Multimodal: estrutura e recursos}

Para elaboração do OA, considerou-se a suposição do canal dual incoporporada na teoria cognitiva da aprendizagem multimídia, onde propõe que o sistema humano de processamento de informação contém um canal auditivo-verbal e um canal visual/pictórico (Mayer, 2005). Dessa forma o OA foi desenvolvido para ser explorado de forma visual e verbal. O OA desenvolvido foi denominado 'Prevenção na Web' (Figura 1) e apresenta medidas e dicas de prevenção e Engenharia Social, tendo como referencial o curso de Informática Instrumental ${ }^{i}$ ministrado na Universidade Federal do Rio Grande do Sul.

O OA foi armazenado em um Ambiente Virtual de Aprendizagem (AVA), o Moodle, contendo diferentes recursos multimídia. O Moodle (Modular Object Oriented Developmental Learning Environment) é um Sistema Open Source de Gerenciamento de Cursos, muito utilizado como plataforma oficial para desenvolvimento de cursos totalmente on-line e/ou como plataforma para comunicação e troca de material entre docentes e alunos (Moodle, 2011). O armazenamento de um recurso educacional, como um OA, em um AVA é fundamental para organização do conteúdo, além do registro das ações do aluno através das ferramentas do AVA. 


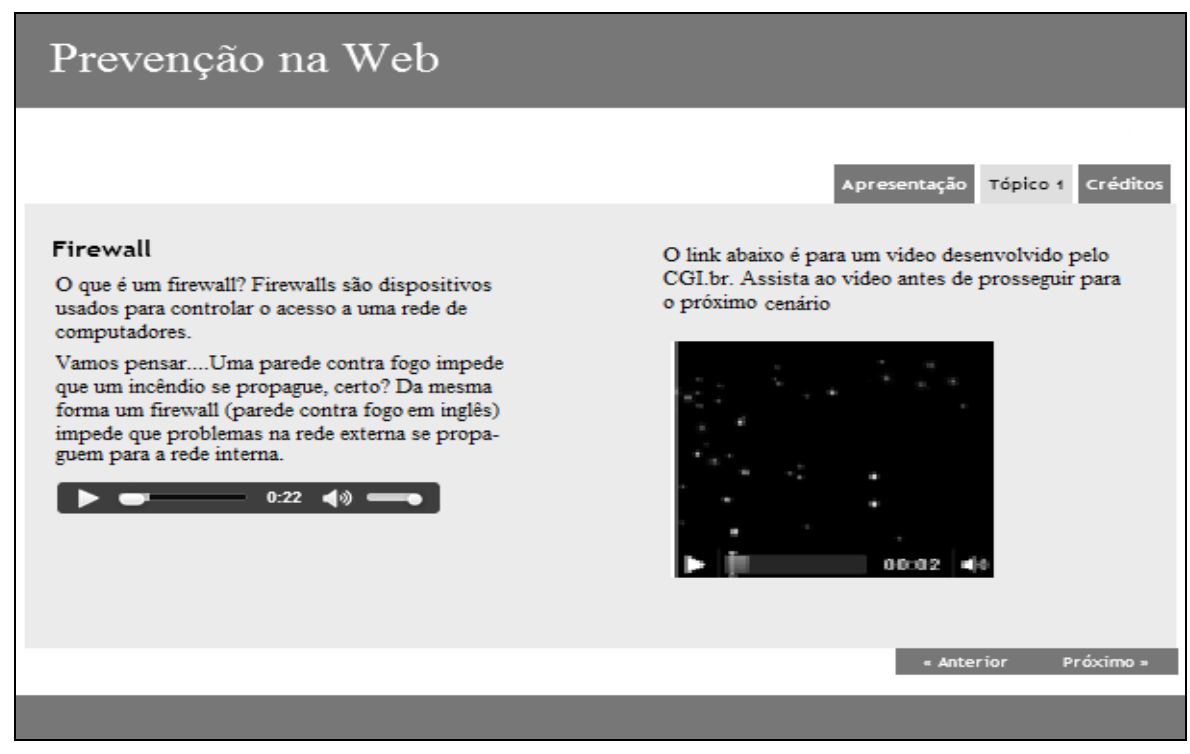

Figura 1- Tela do OA Prevenção na Web

O OA Prevenção na Web possui atividades a serem realizadas através das ferramentas do AVA Moodle tais como fórum, wiki e questionários, permitindo o registro de respostas e fornecimento de feedback aos alunos. Além dessas atividades, alguns exercícios foram elaborados na ferramenta HotPotatoes ${ }^{i i}$ (Figura 2), e usados como objetos "scormizados", armazenados no Moodle e referenciados no OA. Os exercícios foram gerados usando o SCORM para permitir o registro de todas as tentativas do aluno, bem como o tempo utilizado para realizar a tarefa, o escore e a situação da atividade (finalizada, incompleta). O SCORM é um conjunto de especificações e normas que definem a relação entre conteúdos de objetos, modelo de dados e protocolos que permitem o compartilhamento de objetos em sistemas que seguem o mesmo modelo (ADL, 2012). O OA Prevenção na Web foi desenvolvido em HTML 5 e os textos foram incluídos em Javascript. Os vídeos possuem três formatos diferentes, sendo apresentados de acordo com o dispositivo usado para acesso.

Considerando a possibilidade de o aluno acessar o OA através de meios diferentes, inclusive através da mídia impressa, o OA foi materializado em mídia impressa. Mas como permitir que um OA multimodal seja explorado através da mídia impressa? Considerando essa possibilidade o OA foi materializado na mídia impressa com recursos de tecnologia de códigos 2D (bidimensionais), mais especificamente QR Code $^{\text {iii }}$. Com isso, pretende-se aumentar as possibilidades de exploração do OA, isto é, o aluno pode acessar pelo computador, pelo dispositivo móvel e pela mídia impressa contendo QR Code usando um dispositivo, reduzindo as limitações da mídia impressa quando utilizada isoladamente. Em relação ao uso de QR Code na educação, pode-se citar os trabalhos de Ramdsen (2008) que apresenta possibilidades de aplicações de códigos 2D na educação e o de Besana (2010) que apresenta um estudo piloto usando o potencial de códigos 2D para facilitar os processos de aprendizagem.

Para acessar um recurso representado por QR Code na mídia impressa o dispositivo móvel do aluno deve possuir um leitor de QR Code. Se o conteúdo for uma URL será direcionado para um endereço web exigindo o acesso à Internet, o que não ocorre quando o QR Code possui apenas uma informação textual. 


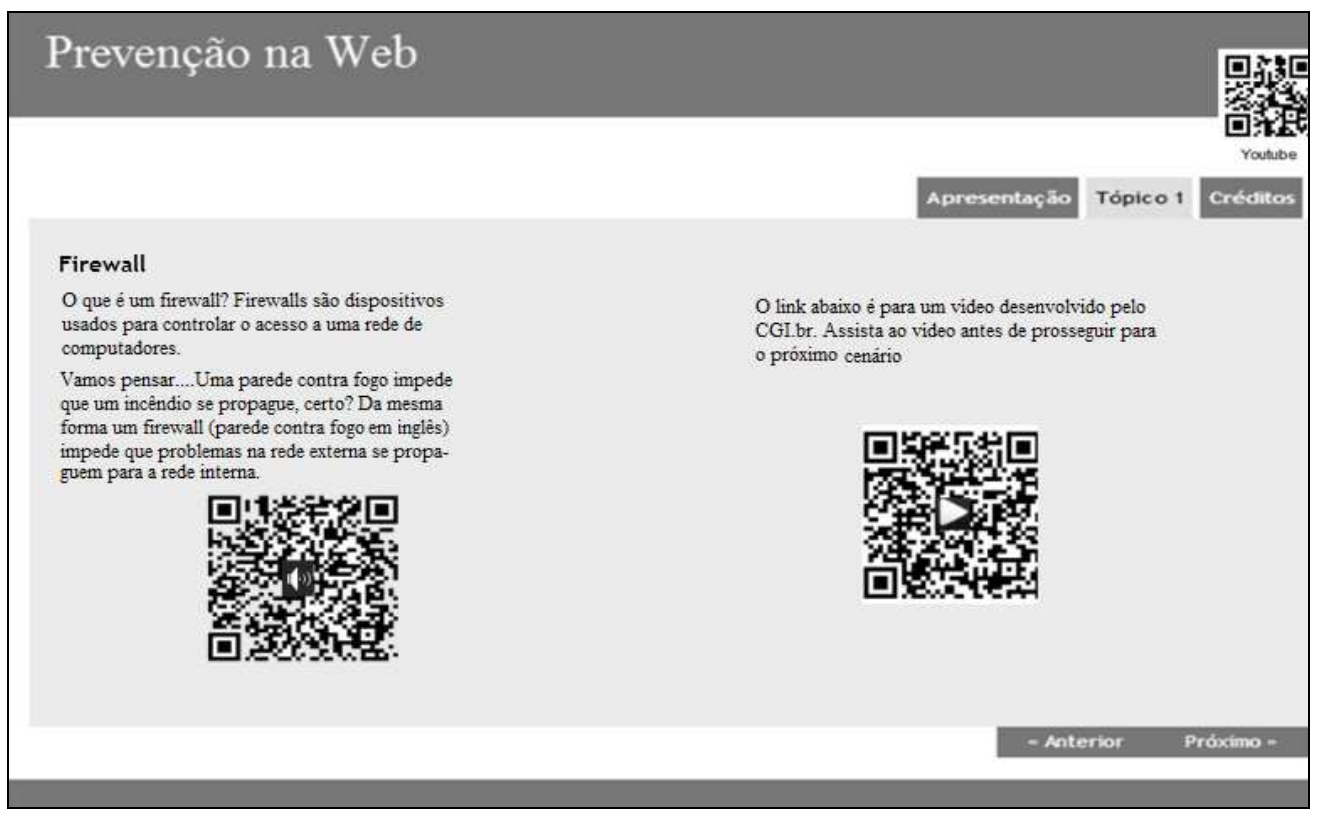

Figura 2 - OA materializado com QR Code

Analisando a Figura 2, observa-se que os elementos dinâmicos (áudio, vídeo, página web) do OA estão representados por QR Code. Dessa forma, o OA materializado com QR Code facilita o acesso aos recursos tais como vídeo, áudio, exercícios, feedbacks, dicas e etc.

\section{Experimento parcial com o OA proposto}

O OA armazenado no Moodle foi utilizado por uma turma de graduação em aula à distância. As orientações foram disponibilizadas no ambiente Moodle e durante a aula à distância o professor utilizou a ferramenta bate-papo para esclarecer dúvidas e fornecer orientação. Os alunos responderam um questionário sobre os meios utilizados para acesso aos conteúdos educacionais, incluindo o computador, a mídia impressa e os dispositivos móveis. Em relação ao uso da mídia impressa os alunos foram questionados sobre os motivos para utilizá-la quando o conteúdo encontra-se disponível digitalmente. $\mathrm{O}$ resultado mostrou que a maioria dos alunos tende a imprimir o conteúdo e os vários motivos são apresentados na Figura 3. 


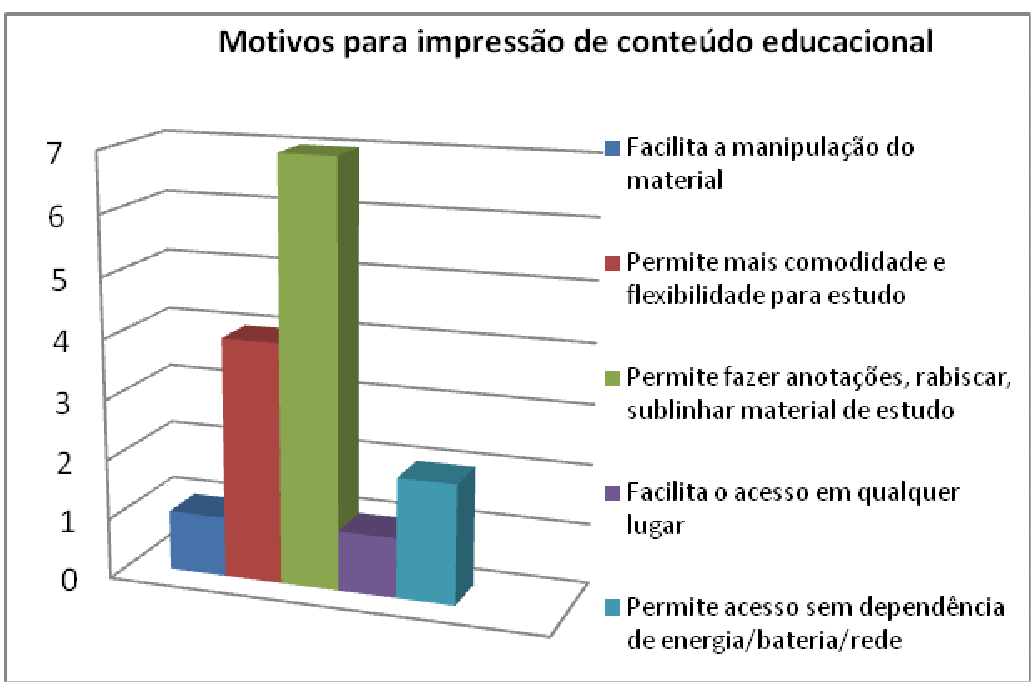

Figura 3 - Motivos para imprimir o conteúdo

Alguns alunos descreveram os motivos para impressão do conteúdo disponibilizado digitalmente, conforme mostram alguns relatos abaixo:

- "Fica mais fácil levar para qualquer lugar, posso fazer anotações"

- $\quad$ "Algumas vezes prefiro ter o conteúdo em papel, pois facilita minha leitura e porque gosto de fazer anotações no próprio material"

- $\quad$ "Para poder fazer anotações importantes em qualquer local, sublinhar dados importantes, etc. Além do que não corro o risco de meu dispositivo móvel ficar sem bateria e eu não conseguir estudar."

- "Acho melhor, pois posso grifar com canetas coloridas e também o manuseio com o papel além do que a luz do computador para leitura me incomoda."

De acordo com os dados da Figura 3 pôde-se observar que mesmo tendo acesso ao conteúdo digital, alguns alunos costumam imprimir o material. Nesse contexto onde os alunos efetivamente costumam imprimir o material educacional, torna-se relevante verificar alternativas para integrar os benefícios do material impresso com a interatividade presente nos recursos digitais.

Considerando o aspecto de mobilidade pode-se perceber que alguns relatos abordam a vantagem da mídia impressa em relação à mobilidade. Apesar dos resultados indicarem que os alunos em algumas ocasiões preferem imprimir o conteúdo, quando questionados sobre o uso de recursos interativos, 37,5\% dos alunos informaram que sentem falta e 33,33\% informaram que às vezes sentem falta da interatividade ao usar a mídia impressa.

\subsection{Aplicação do OA Prevenção na Web}

Na metodologia utilizada para aplicação do OA considerou-se a necessidade de dividir a turma em grupos e disponibilizar o material de modo que cada grupo pudesse acessar apenas o seu material. Dessa forma, utilizou-se a ferramenta 'Grupos' do Moodle. A turma foi dividida em dois grupos da seguinte forma: o grupo A acessou o OA através do computador e o grupo B através da mídia impressa com QR Code. Dos alunos da 
turma, nove alunos participaram da aula à distância. Um grupo (grupo A) foi composto por seis alunos e o outro (grupo B) por três alunos. Na execução do experimento percebeu-se duas limitações, sendo elas: ausência de leitor para decodificação de códigos 2D pelo dispositivo móvel e acesso limitado à Internet.

As instruções foram fornecidas durante a aula pela ferramenta chat do ambiente Moodle. Após estudar o OA os alunos responderam um questionário de interatividade. A análise da interatividade considerou os tipos de interatividade propostos por Moreno e Mayer (2007). Em Moreno e Mayer (2007) são apresentados cinco tipos de interatividade em ambientes educacionais multimodais, resumidos em Tarouco (2009) (Quadro 1):

Quadro 1. Tipos de interatividade em ambientes multimídia educacional (Moreno \& Mayer 2007)

\begin{tabular}{|l|l|}
\hline \multicolumn{1}{|c|}{$\begin{array}{c}\text { Tipo de } \\
\text { interatividade }\end{array}$} & \multicolumn{1}{c|}{ Descrição } \\
\hline Dialogar & $\begin{array}{l}\text { O estudante recebe questões e respostas ou realimentação para } \\
\text { suas reações. Exemplo: Procurar ajuda de um agente na tela, clicar } \\
\text { em um hiperlink para obter informações adicionais. }\end{array}$ \\
\hline Controlar & $\begin{array}{l}\text { O estudante determina o ritmo e/ou a ordem da apresentação. } \\
\text { Exemplo: Uso de pausa / continuar, avançar, etc. }\end{array}$ \\
\hline Manipular & $\begin{array}{l}\text { O estudante estabelece parâmetros para uma simulação, define o } \\
\text { foco aproximação (zoom) ou move objetos no cenário. Exemplo: } \\
\text { Definir parâmetros em um jogo de simulação e executar } \\
\text { a simulação para ver o que acontece. }\end{array}$ \\
\hline Pesquisar & $\begin{array}{l}\text { O estudante encontra novo material colocando uma pergunta, } \\
\text { recebendo opções e selecionando as alternativas desejadas. } \\
\text { Exemplo: Buscar informações em uma pesquisa na Internet. }\end{array}$ \\
\hline Navegar & $\begin{array}{l}\text { O estudante move-se por diferentes áreas do conteúdo } \\
\text { selecionando diversas fontes de informação disponíveis. Exemplo: } \\
\text { Clique em um menu para mover de uma página da Internet para } \\
\text { outra }\end{array}$ \\
\hline
\end{tabular}

O questionário foi elaborado utilizando a escala Likert com as seguintes possibilidades de resposta: $\mathrm{S}$ (Sim), $\mathrm{P}+$ (Parcialmente com poucas restrições), $\mathrm{P}$ (Parcialmente) , P- (Parcialmente com muitas restrições), N (Não). As questões foram respondidas considerando o meio utilizado para uso do OA. O Quadro 2 apresenta as questões. 
7

Quadro 2. Questões sobre a interatividade do OA

\begin{tabular}{|c|c|}
\hline Questão & Descrição \\
\hline 1 & O OA permite visualizar as questões. \\
\hline 2 & O OA fornece feedback das questões respondidas. \\
\hline 3 & $\begin{array}{l}\text { O recurso utilizado para acesso permite entender o conteúdo abordado pelo } \\
\text { OA. }\end{array}$ \\
\hline 4 & OA permite acesso e realização das questões e atividades. \\
\hline 5 & $\begin{array}{l}\text { É possível obter informações adicionais usando as referências (links) no } \\
\text { OA. }\end{array}$ \\
\hline 6 & É possível controlar (iniciar, pausar, retornar, etc.) os recursos do OA. \\
\hline 7 & O OA permite a navegação entre os tópicos e páginas. \\
\hline 8 & O OA oferece controle de mudança de conteúdo (tópicos). \\
\hline 9 & $\begin{array}{l}\text { O OA permite manipulação usando recursos como zoom,movimentação de } \\
\text { objetos, etc. }\end{array}$ \\
\hline 10 & O OA oferece opções de busca para informações adicionais ao conteúdo. \\
\hline 11 & $\begin{array}{l}\text { O OA permite navegar em páginas da Internet permitindo acesso a outras } \\
\text { informações. }\end{array}$ \\
\hline 12 & O OA permite o desenvolvimento de exercícios ao longo do conteúdo. \\
\hline 13 & O OA oferece diferentes tipos de atividades. \\
\hline 14 & $\begin{array}{l}\text { O OA utiliza uma linguagem simples que permite o fácil entendimento do } \\
\text { conteúdo. }\end{array}$ \\
\hline 15 & O OA é fácil de manipular. \\
\hline 16 & O OA sinaliza o conteúdo (tópico) abordado durante a navegação. \\
\hline 17 & A localização dos menus e botões de navegação facilita a interatividade. \\
\hline 18 & $\begin{array}{l}\text { As atividades do OA facilitam a interação (fórum, wiki,etc.) com outros } \\
\text { participantes do curso. }\end{array}$ \\
\hline 19 & Os recursos utilizados para navegação são intuitivos. \\
\hline 20 & Os recursos do OA são úteis para facilitar o entendimento do conteúdo. \\
\hline 21 & Os recursos de áudio do OA foram utilizados. \\
\hline 22 & Os vídeos facilitam o entendimento do conteúdo abordado no OA. \\
\hline 23 & O OA oferece dicas sobre o conteúdo. \\
\hline
\end{tabular}

Em alguns itens do questionário, o uso do $\mathrm{OA}$ através da impressa com $\mathrm{QR}$ Code obteve melhor resultado do que o acesso ao OA pelo computador de acordo com a percepção dos alunos, conforme apresenta a Figura 4 .
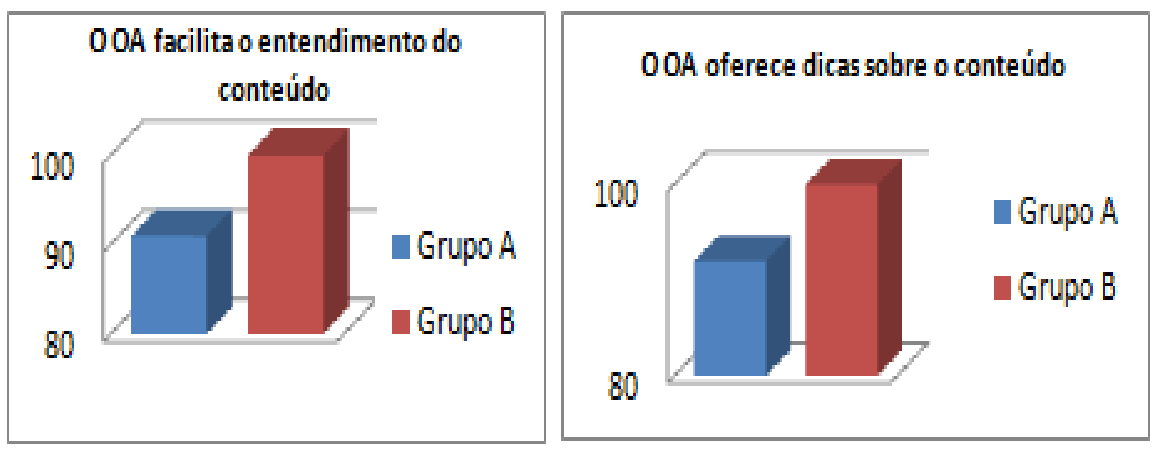

Figura 4 - Itens 20 e 23 do questionário 
A Figura 5 apresenta resultados mais favoráveis ao uso do computador. Vale ressaltar que a funcionalidade referente à navegação entre cenários do OA não foi materializada em QR Code para evitar que o aluno tivesse acesso ao OA completo. Ou seja, o OA impresso com QR Code não apresentou um QR Code para navegação entre páginas, a fim de evitar que o aluno utilizasse o OA diretamente no dispositivo móvel. No modelo proposto os QR Codes direcionam para recursos de uma página permitindo acessar um recurso por vez e não uma página contendo vários recursos.

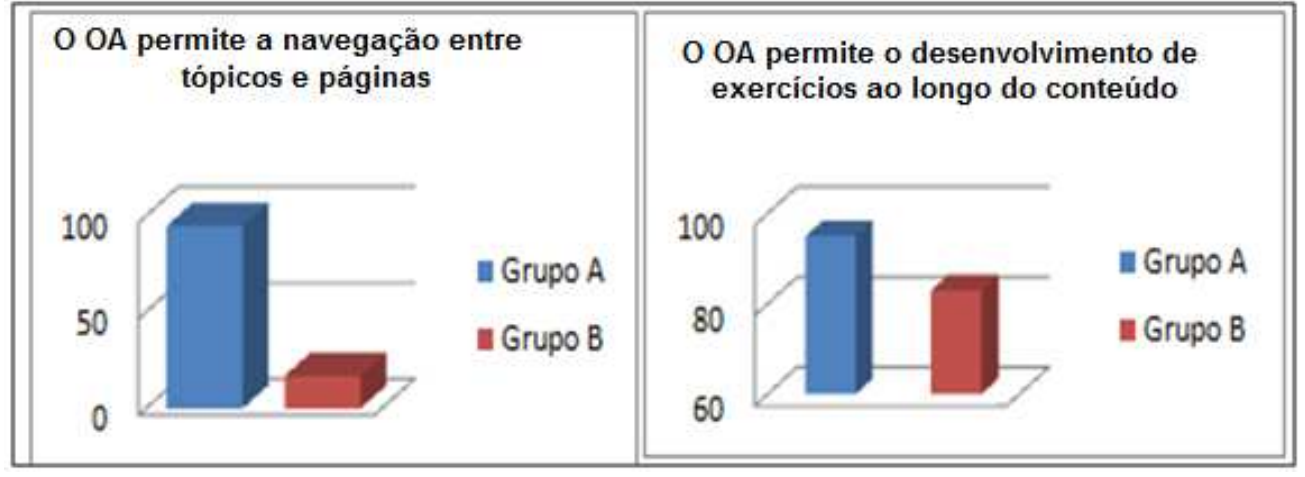

Figura 5 - Itens 7 e 12 do questionário

Em relação aos exercícios, um dos alunos do grupo B relatou a dificuldade ao responder às questões dissertativas e atividades do HotPotatoes. Dessa forma, deve-se analisar quais tipos de questões são mais apropriadas para manipulação, considerando a proposta aqui apresentada.

Ao serem questionados sobre a interatividade do OA, considerando o meio utilizado para acesso e estudo, os alunos do grupo A e grupo B responderam que o OA fornece interatividade, conforme apresenta a Figura 6. Observa-se que na percepção dos alunos do grupo B o OA acessado pela mídia impressa com QR Code e dispositivos móveis apresentou $100 \%$ de interatividade.

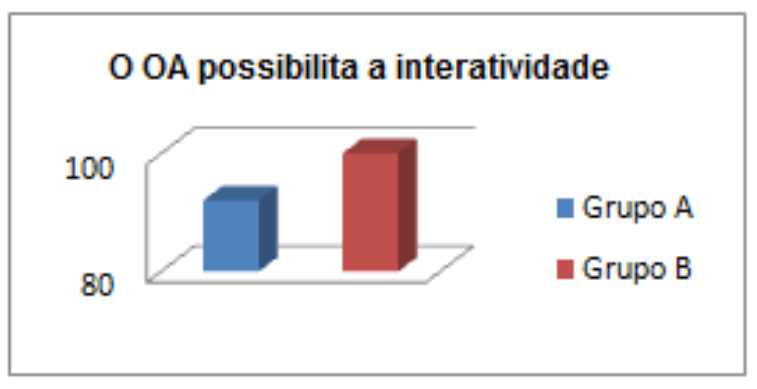

Figura 6 - Resultados do questionário

Vale ressaltar que trata-se de um experimento parcial devido ao número reduzido da amostra. Baseando-se nos dados obtidos, outros experimentos serão realizados a fim de obter dados mais significativos. No entanto, os resultados apresentados podem indicar novas possibilidades de uso de Objetos de Aprendizagem, considerando a aplicação de recursos complementares tais como a mídia impressa, os códigos 2D e os dispositivos móveis. 


\section{Considerações finais}

O artigo apresentou uma proposta de integração de recursos para facilitar o acesso aos OAs Multimodais, inclusive pela mídia impressa. A pesquisa realizada com alunos mostrou que a mídia impressa ainda é muito utilizada. Um experimento parcial foi realizado com alunos de graduação a fim de verificar se a proposta de integração de recursos, incluindo a mídia impressa, propicia a interatividade. Os resultados parciais mostram uma possibilidade de uso dos QR Codes integrados à mídia impressa e acessados por dispositivos móveis, como uma forma de facilitar o acesso aos recursos dinâmicos enquanto se utiliza a mídia impressa para outras atividades. A materialização do OA em mídia impressa com QR Code permite o acesso a todos os recursos (elementos) do OA, usando um dispositivo móvel como complemento. O objetivo não é utilizar apenas um meio para explorar o OA, mas meios diferentes de forma complementar. Serão realizados outros experimentos para validar os dados obtidos nesse experimento inicial. Uma das dificuldades encontradas para realizar esse experimento foi formar um grupo para acessar o OA usando dispositivos móveis em virtude da incompatibilidade dos dispositivos com os leitores de QR Code.

\footnotetext{
' Curso de Informática Instrumental para Professores da Educação Básica - UAB UFRGS, Material elaborado pela Professora Taisy Weber - UFRGS.

ii Software que permite a criação de exercícios interativos - Fonte: http://hotpot.uvic.ca/

iii QR Code é marca registrada da DENSO WAVE INCORPORATED
}

\section{Referências}

ADL. Advanced Distributed Learning. SCORM. Disponível em: http://www.adlnet.org. Acesso em: 09 Jul 2012.

BELISARIO, Aluizio. O material didático na educação a distância e a constituição de propostas interativas, In: SILVA, M. (org), Educação Online, São Paulo:Loyola, 2006. p. $137-148$

BESANA, Stefano. L'uso del QR Code come tecnologia didattica: uno studio esplorativo. TD-Tecnologie Didattiche, 51, 2010. pp. 34-40

CENSO Ead.br (2010) Censo ead.br / organização Associação Brasileira de Educação a Distância. São Paulo: Pearson Education do Brasil.

MASETTO, Marcos. Mediação pedagógica e o uso da tecnologia, In: Novas tecnologias e mediação pedagógica, Moran, J.M., Masetto, M.T., Behrens,M.A., SP:Papirus, $13^{\mathrm{a}}$ ed. 2007.

MAYER, Richard. Introduction to Multimedia Learning. In: MAYER, R. E. (Ed.). The Cambridge Handbook of Multimedia Learning. New York: Cambridge University Press, 2005. p.1-18. 
MOODLE, Moodle, 2011 Disponível em http://moodle.org/about/ Acesso em: 10 de fev. 2011

MORENO, Roxana, MAYER, Richard. Interactive Multimodal Learning Environments, Special Issue on Interactive Learning Environments: Contemporary Issues and Trends, Educ Psychol 2007. Rev 19:309-326.

RAMSDEN, Andy. The use of QR-Codes in Education: A getting started guide for academics. Online Publications Store, University of Bath Opus 2008. Disponível em: < http://opus.bath.ac.uk/> Acesso em 15 Set. 2010.

TAROUCO, Liane Margarida Rockenbach et al, Multimídia Interativa: Princípios e Ferramentas, RENOTE- Novas Tecnologias na Educação, V. 7 No 1, Julho, 2009. 